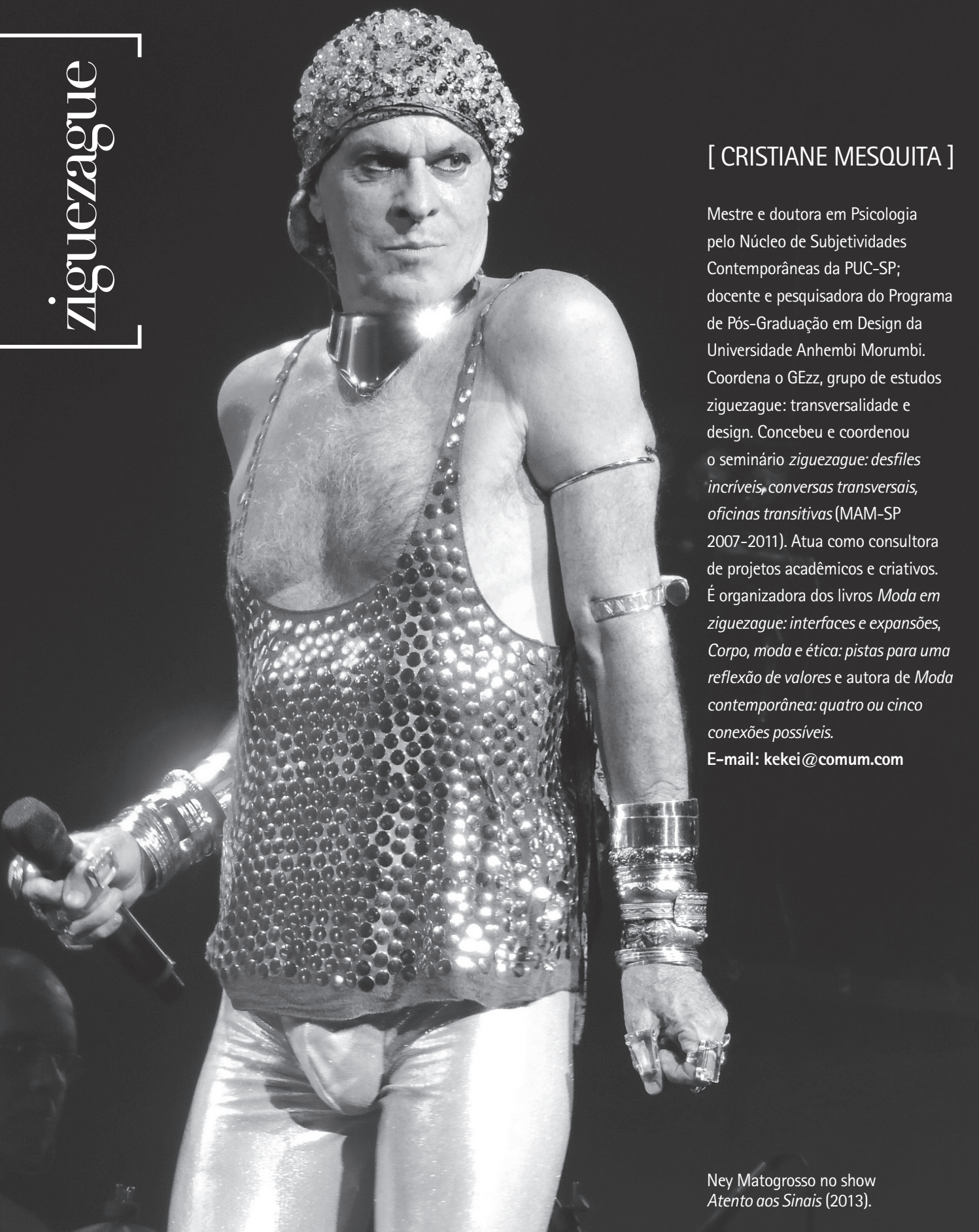

\title{
Em ziguezague entre Ney Matogrosso e Flávio de Carvalho
}

A oitava edição do ziguezague: desfiles incriveis, conversas transversais, oficinas transitivas ${ }^{1}$ contou com uma presença muito especial: Ney Matogrosso². Aos 71 anos de idade, 33 discos lançados e uma vivacidade impressionante, Ney é um artista que nunca se esgota, graças à sua liberdade artística e veia camaleônica. Além de ser um dos maiores intérpretes musicais do Brasil, o cantor é exuberante e seduz um público diversificado com apresentações vigorosas, performances marcantes e figurinos singulares. ${ }^{3}$

Imagens de um de seus trajes mais emblemáticos integraram a exposição em cartaz no Museu naquele momento, $A$ cidade do homem $n u_{1}^{4}$ uma curadoria do colombiano Inti Guerrero. A mostra foi inspirada em conferência ministrada pelo artista 
e arquiteto brasileiro Flávio de Carvalho (1899-1973) em 1930, no IV Congresso Panamericano de Arquitetura e Urbanismo, no Rio de Janeiro. Nesse texto, ${ }_{1}^{5}$ Carvalho propôs um "urbanismo para o homem nu" - leia-se desnudado do seu corpo cultural - e uma "nova cidade", onde a sexualidade cumpriria papel fundamental.

Além dessa mostra, a retrospectiva da obra de Flávio de Carvalho, ${ }^{6}$ com curadoria de Rui Moreira Leite, ocupava a sala principal do MAM e também conduziu as atividades daquela edição do ziguezague. As reflexões de Carvalho sobre a roupa, publicadas no jornal Diário de São Paulo no período de 04/03/1956 a 21/10/1956, com o título Casa, homem e paisagem: ensaios sobre a moda masculina, originaram a performance chamada Experiência $n^{\circ}$ 3, realizada em 18 de outubro de 1956, no centro da cidade de São Paulo. Flávio de Carvalho vestiu blusa de mangas curtas, saia acima dos joeIhos, meias arrastão, sandálias de couro e chapéu e desfilou pelas ruas, propondo uma nova concepção de indumentária para os homens tropicais, o "traje de verão". Em torno dessas ideias caminharam as propostas de trânsito entre moda e arte daquela edição, pontuadas por questões que atravessam a masculinidade, a roupa, a cidade, a ocupação urbana, a performance e a arte como experiência.

Para conduzir a conversa com Matogrosso, convidei o jornalista Jackson Araújo, especialmente por sua ligação singular com a música. A partir de alguns fragmentos do texto de Flávio de Carvalho, ele orquestrou nosso encontro. Parte dessa conversa transversal foi transcrita ${ }^{8}$ e editada para compor esta edição da coluna. Desde aquela manhã que emocionou o público que lotava o auditório - alguns chegaram às lágrimas - desejei fazer com que algumas das palavras do artista reverberassem mais e mais. É essa dObra que fazemos aqui.

JA: Ney é uma figura que dispensa apresentações. Ele tem uma relação muito importante na construção do imaginário artístico do Brasil, a partir da música. É relevante ressaltar sua relação com o figurino e com a performance e pensar a experiência de um homem que se reinventa, portanto, vale falar da construção do mito. Flávio de Carvalho nos diz: "O homem livre despido de tabus vencidos produzirá coisas maravilhosas, a sua inteligência criará novos ideais, isto é, novos tabus. 0 seu ego se relacionará automaticamente em grupos, procurando caracterizar em cada grupo uma serie de tendências". Como era o Ney Matogrosso antes dos Secos \& Molhados? ${ }^{10} 0$ que ele vestia? Como se comportava? 0 que veio do "Ney Matogrosso pessoa física" para a "pessoa jurídica Secos \& Molhados"?

NM: Desde que me entendo por gente, contrario as regras. Nos anos 1960, no Rio de Janeiro, saía de camisetinha regata e as pessoas me xingavam, quase "jogavam pedras". Não entendia como no Rio de Janeiro - uma cidade tão quente - não se podia usar uma camiseta assim. Depois vim morar em São Paulo. Era hippie e não tinha dinheiro para comprar sapatos. Comprei um par de tamancos de um português e com eles andava pelas ruas. As pessoas xingavam e batiam a janela na minha cara. Pensava nos porquês. Por que me xingam? 0 que significa isso? Quando lançaram a sandália havaiana, achei que era uma libertação,

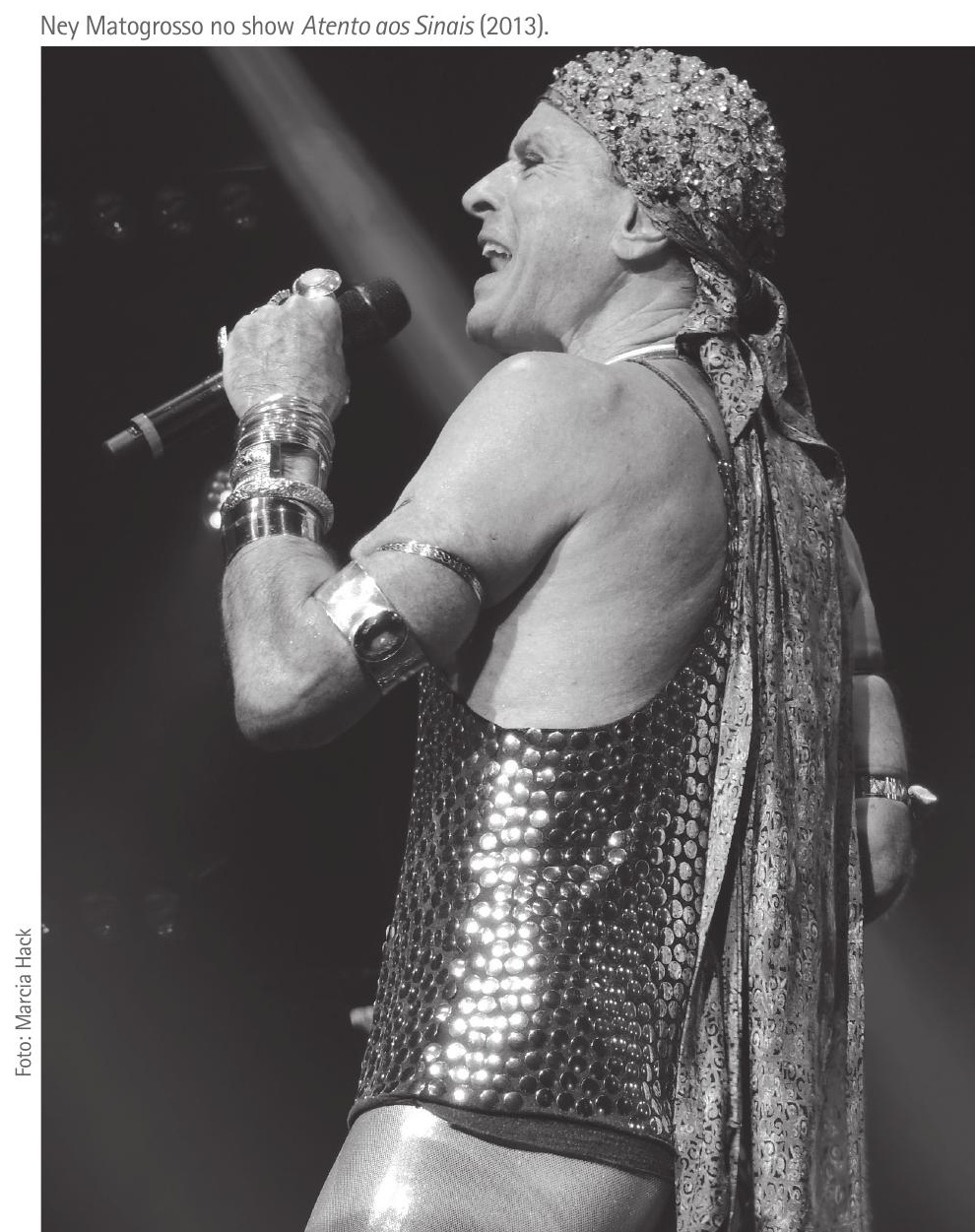


porque homens só andavam de sapato, não existia outra possibilidade. Graças a Deus libertaram o pé da gente! Comprei um par de sandálias e fui à casa da minha tia. Ela me expulsou, dizendo: "Nunca mais volte aqui com seus pés de fora". Eu não compreendia, porque não considerava que alguém fosse mais ou menos homem porque estava com os pés de fora. Tudo isso aconteceu muito cedo, quando eu tinha 17, 18 anos. Daí para a frente, alguma coisa em mim se soltou. Eu pensava: "Não estou nem aí pro mundo, vou viver da maneira que eu quiser, vou me vestir como eu quiser, vou ser a pessoa que eu quiser".

JA: E então você foi parar nos Secos \& Molhados, construindo os figurinos, desenhando suas roupas? A pintura facial foi uma forma de esconder sua timidez?

NM: A pintura facial partiu do fato de que me diziam que artista não podia andar na rua. Eu tinha 31 anos e não queria perder esse direito, porque adoro rua! Inspirado pelo teatro, fui até uma loja especializada em maquiagens e comecei a criá-las. Cada vez que me apresentava, inventava uma maquiagem diferente. Sendo uma pessoa muito tímida, a partir do momento que eu perdia meu rosto, adquiria uma coragem que não conhecia, embora já existisse. Eu já era uma pessoa que enfrentava manifestações contrárias, mas eu não sabia que poderia ser ainda mais combativo.

JA: A máscara, então, funcionava como um elemento de libertação do corpo?

NM: Sim. Eu não tinha rosto, eu não era alguém, eu era livre.

\section{JA: Isso também te deu liberdade para ficar nu?}

NM: Sim, completamente. Sem nenhuma vergonha, embora anteriormente eu tivesse vergonha das minhas mãos, dos meus pés e não ousasse trocar de camisa na frente de alguém. Vai saber o que aconteceu...

CM: No senso comum, fala-se tanto de "afirmação da identidade", e você diz: "quando eu perdi meu rosto, adquiri uma coragem incrível".

NM: Sim, adquiri uma liberdade corporal da qual não tinha conhecimento.

JA: Interessante pensar melhor sobre a máscara da maquiagem, que é um elemento importante na construção de uma imagem de moda. E sua maquiagem mudou com o tempo, até você decidir ficar sem maquiagem.

NM: Recentemente, revi fotos dos Secos \& Molhados. Primeiramente, fiquei chocado, porque não me reconheci. Pensei que não sou eu, não sou aquilo. Por outro lado, entendi que aquela imagem é muito forte e que sempre cabe a mim conduzi-la, pois atingia algo do inconsciente das pessoas. Sempre escolho a primeira fotografia que será relacionada a algum trabalho. Depois perde-se o controle, mas a primeira imagem é muito importante, pois estabelece aquilo que mais desejo mostrar ao público.

JA: Ney Matogrosso fluiu dos Secos \& Molhados para a carreira solo, para a construção de um novo mito. Houve uma ruptura de linguagem? Você continua sendo o mesmo Ney Matogrosso? Existe o Ney Matogrosso que andava de tamanco, xingado pelas pessoas; existe o Ney Matogrosso dos Secos \& Molhados, que colocou a máscara, perdeu o rosto e teve coragem de ficar nu; e existe o Ney Matogrosso atual, agora numa carreira solo. Relaciono esse "novo mito" a outro fragmento do texto de Flávio de Carvalho: "A sua índole repele o passado, porque no passado nada viu senão a repetição de dogmas inconvenientes. Ele deseja saltar fora do círculo e abandonar 0 movimento recorrente e destruidor de sua alma, procurar o mecanismo de pensamento que não entrave o seu desejo de penetrar no desconhecido"11.

NM: Sempre caminhei para a frente. Nunca fiquei preso ao passado, nunca tive medo do que poderia vir. Quando saí dos Secos \& Molhados, fiz um figurino de crina de cavalo e ossos. Li sobre feiticeiros africanos, sobre o modo como eles usavam ossos e chifres que funcionavam como para-raios contra forças negativas. Ricardo Zambeli era quem fazia meus primeiros figurinos. Eu tinha que ficar em pé em sua frente 0 dia todo, para que ele construísse as peças sobre o meu corpo. A primeira roupa que usei era uma imensa pele de onça parda, transformada sobre mim: as pernas da onça eram minhas pernas, as mãos da onça eram meus braços, a cabeça era minha cabeça. Ele fez o colete de crina de bode e atendeu meu pedido para usar os chifres de carneiro, enrolados como se fossem asas. Os chifres são para-raios. Depois quis outras 
coisas para o lançamento de Bandido: sem maquiagem para me esconder, embora me sentisse muito inseguro por estar deixando o grupo que havia sido um fenômeno no Brasil. Eu tinha certa insegurança, era muito tenso porque tinha medo da reação das pessoas. Não queria ser rejeitado. Depois comecei a entender que não precisava ser sério. Quando percebi a aceitação, comecei a relaxar no palco.

JA: Bandido foi um álbum caliente e romântico. Pecado é um tanto quanto conceitual. É o meu favorito.

NM: Sim, sem dúvida. 0 meu também. 0 Bandido é o mais sexual de todos os discos que já fiz. Ali eu tirava a bota, lambia o salto, fazia um striptease total. Havia um biombo de madeira, atrás dele eu trocava de tapa-sexo e ficava na ponta dos pés, mostrando os pentelhos. As pessoas viam que eu estava completamente nu. Nunca mais fiz isso. Eu faço striptease, brinco, de vez em quando, mas nunca mais da maneira tão radical como foi no Bandido.

JA: E como é que você consegue o controle da imagem sendo um artista que se expõe? É você quem cria suas imagens?

NM: Sim, sou eu quem cria. Não contrato ninguém para construir minha imagem. No show Inclassificáveis, trabalhei junto com Ocimar Versolato. Eu idealizei a imagem e ele realizou. Vi um programa sobre a América Central que falava sobre um Imperador Asteca ou Maia que mergulhava no lago Titicaca, coberto de ouro, para oferecê-lo aos deuses. Achei essa ideia interessante, ela me remetia a um arquétipo latino-americano. Contei a história ao Ocimar e perguntei: "Como posso estar nu e, ao mesmo tempo, pintado de ouro"? Ele pensou na segunda pele. Era um tecido transparente e elástico. Com a luz sobre a roupa, parecia que saiam labaredas do meu corpo.

CM: Eu queria retomar aquilo que você lembrou sobre o erotismo. Isso porque Flávio de Carvalho e você foram referências para conduzir essa edição do ziguezague. Na conferência dele, num congresso de Arquitetura em 1930, ele reclama uma cidade menos carregada do peso da história da cultura ocidental. Ele vibra por uma cidade mais erotizada, por espaços que favoreçam a erotização. Penso que você, como artista, coloca isso de modo muito especial. Queria que você falasse um pouco mais de sua relação com o erotismo.

NM: Desde a primeira vez que pisei no palco com os Secos \& Molhados, a carga erótica foi um desafio. No show 0 Homem de Neanderthal, existia a nudez, mas não existia erotismo, porque eu estava muito tenso e preocupado. Ali, na verdade, eu era um bicho. Quando fiz o Bandido, resolvi que seria mais humano, que seria um homem livre. Mas a sexualidade explícita era permitida e exigida das mulheres. Os homens jamais podiam expressar sua sexualidade. E pensei: por que não? Sou um homem sexualizado, porque que não posso mostrar isso para as pessoas? As pessoas escondem a sexualidade, e eu exacerbei. Aquilo era verdade, não era um tipo. Eu era uma pessoa que não dormia se não praticasse sexo. Olhava a plateia e desejava a plateia. Se pudesse transar com aquelas pessoas todas, eu transaria. Eu imaginava que aquilo fosse um ser só. E eu queria aquele ser.

CM: Assim, você explorava outras formas de

\begin{abstract}
Ney Matogrosso no show Beijo Bandido (2011).
\end{abstract}

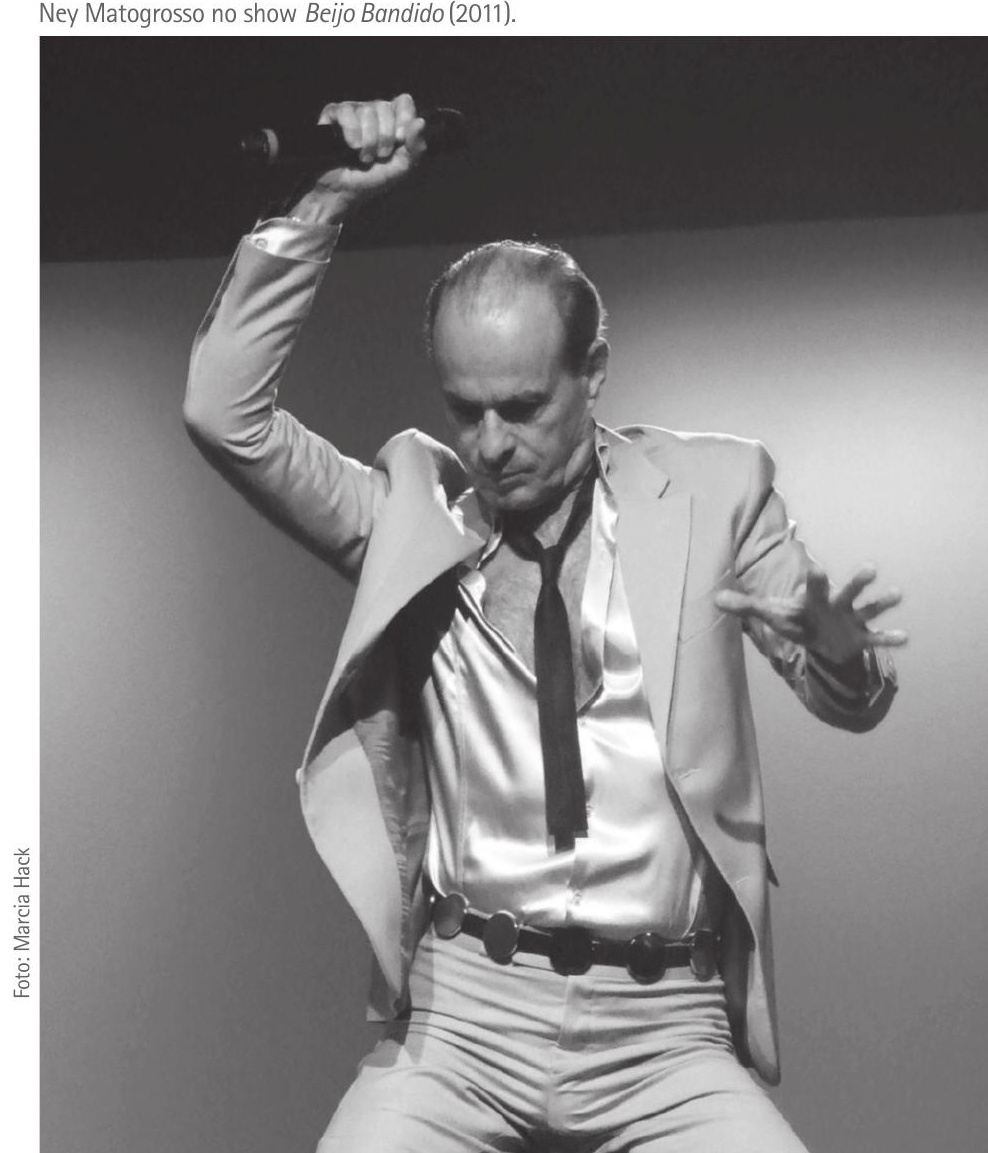




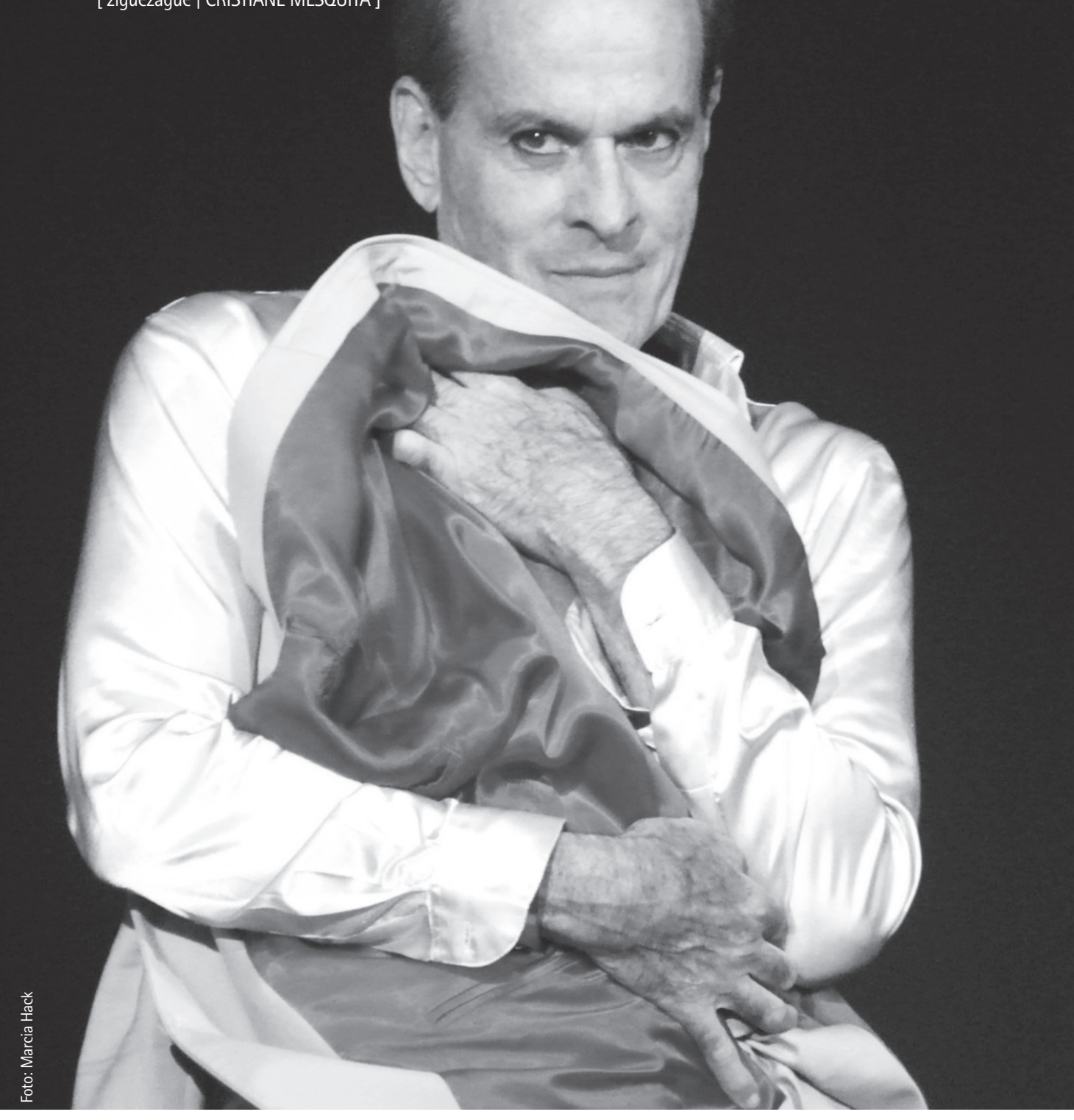

Ney Matogrosso no show Beijo Bandido (2011).

erotismo, mais diluídas.

NM: Sim. Era dirigido para todas as pessoas. Não era para homens ou mulheres, ou para velhos ou jovens. Era oferecido para todas as pessoas. Hoje em dia, é mais uma brincadeira, mas existe ainda a carga erótica.

JA: Muda o personagem, muda o figurino, mas a sexualidade existe.

NM: Sim, mas não é mais daquela forma. Agora posso brincar sobre esse tema.

JA: No Museu do Ouro, em Bogotá, há uma sala muito interessante, que explicita uma oferenda que as civilizações arcaicas faziam, jogando uma vez por ano todo o ouro que tiravam da natureza. Essa questão da oferenda perpassa seu figurino como referência, mas em que ponto ela encontra sua performance?

NM: 0 tempo todo. Estou ofertando o tempo todo. Na hora em que a cortina se abre, estou me ofertando. Antes de entrar em cena, foco alguma coisa que entra pelo topo de minha cabeça, que chega no peito e que se expande. Mentalizo que algo me atravessa, que passa por dentro de mim e que sai de mim para a plateia.

JA: Essa inquietude te mantém criativo?

NM: Nunca estou satisfeito, sempre quero mais. Mas esse "querer mais" é egoísta, pois não penso só no público. Penso em manter meu prazer para oferece-lo à plateia. É uma constante transformação para me manter interessado. Mantendo-me interessado, posso manter-me interessante.

CM: Gostaria de enfocar a performance. Inclusive a partir de sua vivência nas cidades, com os pés calçados pelas sandálias. Flávio de Carvalho, em 1956, fez a performance chamada Experiência $n^{\circ} 3$, quando saiu pelas ruas de São Paulo, vestido com 
o que chamou de "new look": saia, meia arrastão e sandálias, porque achava que o homem dos trópicos não poderia andar vestido de maneira convencional. De algum modo, sua história de vida e de palco sempre foi uma situação performática "inclassificável". Esse título é muito propício ao seu trabalho. Você é generoso, porque essa doação - por mais que ela tenha esse trânsito entre você e seu próprio prazer - é uma situação de disposição, uma situação de estar em performance.

NM: E sempre é uma situação de risco.

\section{CM: Como é esse risco?}

NM: Adoro correr riscos. Se não há riscos, acho desinteressante. Quando fiz Inclassificáveis, foi um enorme sucesso. Então, pensei: agora vou fazer o contrário, vou cantar clássicos da música brasileira vestido de terno.

CM: É o movimento "inclassificável".

JA: É transformação. É trazer sempre um novo elemento, um novo componente. $\dot{E}$ como a moda, que de seis em seis meses faz uma espécie de negação para se manter viva e pulsante. Reiventa cores e formas. Como artista, você não se movimenta com tanta metodologia, mas existe a inquietude que te faz propor um susto, uma surpresa.

NM: Uma transformação total.

\section{JA: Sem perder o DNA da marca Ney Matogrosso.}

NM: Patenteada pela minha pessoa, pelos meus pensamentos. Porque não uso um terno para estar chic, mas sim como uma fantasia. Embora o terno seja lindo e bem cortado, o formato da calça em "V" exibe meu corpo. Gosto de me exibir. É proposital.

\section{JA: Você está vestido, porém nu.}

NM: Sim.

\section{JA: Há alguma história especial sobre seus figurinos?}

NM: Tudo tem algum significado pra mim. Algumas peças que visto me dão poderes. Eu sinto. As orelhas de ouro da imagem que está exposta tinham diamantes nas pontas. 0 primeiro figurino dos Secos \& Molhados com franjas me fez perceber que a roupa dá amplitude ao gesto. Os balangandãs fazem o gesto ficar maior, de modo que posso triplicar o tamanho da ação. Quando usava a peruca de crina de cavalo, me tornava uma entidade latino-americana. Não sabia mais quem eu era, eu era remetido aos Andes.

JA: Podemos entender os adornos, os acessórios, os ornamentos como substituição da maquiagem? As orelhas, por exemplo, te davam o mesmo que a máscara te dava?

NM: Não exatamente, pois a máscara me ocultava, e os acessórios não. Mas são peças que conferem poder. Como os chifres nos ombros, usados por feiticeiros africanos para ficar mais poderosos. Eu usava com a mesma intenção.

CM: Lembro-me de uma antropóloga, a Regina Muller. Ela disse numa entrevista: "Ponha roupa que o santo vem". Acho que a sua figura explora essa ideia que as pessoas exercitam diariamente, em outro grau de força.

NM: Libero meu inconsciente para captar energias, intencionalmente. Estou sempre aberto e receptivo. Se você se abre, você recebe. E a gente recebe poderes não apenas do figurino. Recebemos tudo aquilo que pretendemos.

JA: 0 ato de receber é uma conexão do artista com o cosmos?

NM: Sim. Não me coloco diante do sol apenas para me bronzear. Coloco-me diante do sol, aberto para receber as informações eletromagnéticas que ele emana. Quero que os raios passem por mim, que me informem em nível inconsciente ou consciente. Isso vai produzir resultados. É uma espécie de ritual pagão.

JA: Flávio de Carvalho diz que "A religião tem o seu lugar adequadamente localizado na zona erógena, sendo ela uma forma de erotismo".12 0 Ney artista se mistura com sua vida pessoal?

NM: Sim, meu trabalho se mistura com a pessoa que sou. É um mérito meu, pois tenho a capacidade de estar aberto para que as coisas me toquem. Isso é algo que a meditação transcendental e a yoga propõem. Não pratico yoga, mas tenho essa abertura. Acho que tudo se mistura numa certa instância, tudo se liga, se relaciona, 
que esse passarinho chega perto de mim eu tenho um frêmito! Ele olha nos meus olhos como se perguntasse: "quem é você?". Vive solto na Mata Atlântica e não vai embora de casa. Um dia, alguém foi em casa e colocou o passarinho numa gaiola. Soltei e de novo ele não foi embora. Passa o dia inteiro solto, voa para lá e para cá. Agora outros passarinhos estão invadindo a casa e voam lá dentro. Considero que isso é uma espécie de "passe", de benção que recebo. Isso faz parte de minha relação com natureza, do meu acesso aos poderes por meio da natureza.

CM: Essa força é visível em você.

JA: Mais uma de Flávio de Carvalho: "O continente americano não herdou do passado o recalque trágico da filosofia escolástica; ele possui elementos próprios para criar uma civilização nua, um novo mecanismo despido dos tabus da velha Europa, uma renovação científica e estética que o colocará na vanguarda da organização humana"133 Como a questão da tropicalização nos modos de vestir te influencia?

NM: Totalmente. Meu maior orgulho é ser latino-americano.

JA: 0 bicho: passarinho, arara, pavão, cavalo, todos esses elementos na natureza... NM: Tudo, tudo tem a ver com a natureza latino-americana...

JA: Mato Grosso! A água...

NM: Brasil, Centro-Oeste desconhecido, cerrados maravilhosos, isso é muito forte. Quer me ver feliz? Me leve ao cerrado, me deixe em lugares a que ninguém quer ir...

JA: Pois bem, espero ter contribuído para fazer conexões entre natureza, moda, arte, música, performance. Deixo outra citação de Flávio de Carvalho. Entendo que ela costura nossas conversas de hoje com essa pessoa magnífica que é Ney Matogrosso. "Convido os representantes da América a retirarem suas máscaras de civilizados e pôr à mostra as suas tendências antropofágicas, que foram reprimidas pela conquista colonial, mas que hoje seriam o nosso orgulho de homens sinceros..." 14 .

NM: Confesso que não conhecia muito sobre Carvalho. Eu era adolescente quando ele fez essa performance. Lembro vagamente, mas não tinha conhecimento do trabalho dele. Com essas frases brilhantes, vejo a enorme afinidade que há entre nós.

\section{NOTAS}

${ }^{[1]}$ Realização do MAM-SP e do Senac São Paulo, ocorrida entre 9 e 12 de junho de 2010.

${ }^{[2]}$ Ney de Souza Pereira nasceu em $1^{\circ}$ de agosto de 1941, em Bela Vista, Mato Grosso do Sul.

${ }^{[3]} 0$ Centro Universitário Senac - Campus Santo Amaro - recebeu em 2010 a doação de todo o acervo de peças do cantor Ney Matogrosso. A instituição acordou a montagem de um espaço de pesquisa, parte da Modateca localizada na Biblioteca, intitulado Espaço Ney Matogrosso. Em 2012, para a inauguração desse espaço, o cantor realizou dois shows para a comunidade acadêmica e abriu a exposição Cápsula do tempo: ruptura no vestir de Ney Matogrosso, com curadoria de Milton Cunha. Atualmente, a coordenação da rede de bibliotecas está levando a exposição para outros Senacs e instituições parceiras. Oportunamente, a webpage da Modateca e do Espaço Ney Matogrosso apresentará todos os detalhes sobre o processo de doação, restauração e catalogação do acervo do cantor, que totaliza 220 itens.

${ }^{[4]}$ Disponivel em: <http://www.mam.org.br/projetos/a-cidade-do-homem-nu/>. Acesso em: 5 abr. 2013.

${ }^{[5]}$ CARVALHO, F. Uma tese curiosa: a cidade do homem nu. In: CARVALHO, F.; GUERRERO, I. Catálogo da exposição A cidade do homem nu. Museu de Arte Moderna de São Paulo. São Paulo, 2010.

[6] Disponivel em: <http://www.mam.org.br/projetos/flavio-de-carvalho/>. Acesso em: 5 abr. 2013.

${ }^{[7]}$ Identificado ao longo do texto como JA. Jackson Araújo é comunicólogo especializado em Moda, eleito como Melhor Jornalista de Moda do Brasil pelo Prêmio Abit 2002. Atua como Consultor Criativo e de Conteúdo, presta consultorias para empresas e grandes grupos desse segmento. Multimídia, dirige a radioblogue Shhh.fm, onde trata a música como principal fio condutor de movimentos culturais, reverberando em relações de consumo, experiências sociais e espaciais. É autor da biografia de Lino Villaventura (Coleção Moda Brasileira, Cosac Naify, São Paulo, 2007).

${ }^{[8]}$ Transcrição realizada por Mariana Arruda Simoni. Mestranda em Design pela Universidade Anhembi Morumbi. Graduada em Design de Moda pela Universidade Anhembi Morumbi (2011). Experiências na área de Design de Moda, como assistente de estilo e assistente de criação em publicidade. É vegetariana e cidadã do mundo. Assina coluna de moda para o jornal Gazeta de Cosmópolis desde 2009 e o blogue <www.pencefundamental.com.br>.

${ }^{[9]}$ Carvalho (2010, p. 22-23).

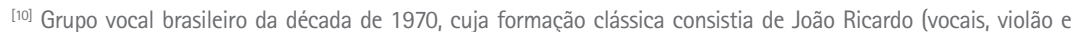
harmônica), Ney Matogrosso (vocais) e Gérson Conrad (vocais e violão).

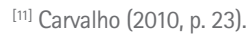

[12] Carvalho (2010, p. 28).

[13] Carvalho (2010, p. 29).

[14] Carvalho (2010, p. 29). 